\title{
Linguistic Deviation in Business Advertisements
}

\author{
Marine Yaghubyan \\ Yerevan State University
}

\begin{abstract}
Advertising can be regarded as a means of persuading consumers to take action with respect to products, ideas or services. It is a complex phenomenon because it involves two interacting processes, namely, communication and persuasion, and both processes are many-faceted. When advertisers intend to make the advertisement language creative and inventive, they use language different from the linguistic norm. Being unconventional, the advertisements which adopt deviation can give the readers unexpected surprise and make a strong impression on their mind. This kind of language phenomenon is technically called linguistic deviation. Then based on some scholars' classifications, the author classifies different deviations in advertising (deviation of phonology, graphology, lexicon, and grammar) and illustrates each deviation with some typical examples.
\end{abstract}

Key words: advertising, business advertisement, linguistic deviation, headline, subheads, body, slogan, phonology, graphology, lexicon, grammar and collocation.

\section{Introduction}

Advertising is a form of communication that is rooted deeply into our life. It can be seen as present in every aspect of life throughout the day, right from the time we wake up until we go back to sleep and at times even in the sleep as subconscious dreams. Advertisements are smart, clever and entertaining puzzles that have been created to catch the immediate attention of the target and leave a lasting impression in their mind (Yule 2006:54). 
The principles of advertising texts can be spelled as: attention value, readability (by means of simple, personal, and colloquial style), memorability (most important in the process of advertising is to remember the name of the product) and selling power (Leech 1972:132).

The deviation of an expression from the expectation of the audience does not really mean that the expression is going to be rejected as nonsensical or faulty, since the deviation occurs at the form level rather than the content level. This article attempts to give a description of language deviations in English advertising, including phonological, graphological, lexical, and grammatical deviation.

\section{Persuasive Function of Advertising}

Advertising is a technique used to reach out to the potential customers. The companies advertise to create demands through wants and needs creation and to attract the existing customers towards their brand. It is a form of persuasion which is directed at large numbers of people, accounts for almost a large space of our daily newspaper and a large proportion of the viewing time of TV (Laspasanska 2006:78).

The most distinctive feature of an advertising language can undeniably be accepted as its capability to stay in sync with the current trend and to reinvent itself continuously, in order to come up with distinctive shapes and to craft totally unforeseen surprise elements for receiving full attention of the audience (Vasiloaia 1996:89).

The advertisers have to come up very quickly with original and unique ways to formulate and deliver the message. It is important to design the communication creatively and cleverly enough so as to stand out of this huge clutter of advertisements and make a mark in the target's cognitive structure, since the primary aim of advertising is to gain the attention of the target with the intention of stimulating the recognition and recall of the advertised brand (Pearson, Nelson 1994:167).

In advertisements three important terms are being taken into consideration: headline, subheads and body. 
Headline is considered the part of print advertisement with prime importance. It is defined as a term that refers to the set of words in the foremost position of any advertisement. The primary role of any headline is to attract the attention of the audience and to be memorable for them.

Subheads can be seen as small headlines with a purpose to communicate the key pointers of the sales pitch. As it is believed, the majority of the audience read only headline and subheads, therefore it is important to construct them in a way that the sales message gets conveyed and gets registered into the reader's cognitive structure for some time in the future.

Body is written to tell the complete story that is to communicate the sales pitch in detail, as a logical continuation of the headline and subhead. Apart from headline, subhead and body there is another important term that is given special attention to while writing any advertisement. It is the slogan of the advertisement. Through continuous usage these headlines or slogans become standard statements that are used on an everyday basis. Slogans are responsible for stability in a campaign and help by summarizing the key idea or message, that the company wants to be associated to its product brand or itself, into a brief statement. Most advertising slogans gain their effect by manipulating the linguistic norms of everyday language. An effective slogan is short, simple, memorable, easy to repeat, and helpful in differentiating the product or the company from its competitors. The alternative terms for advertising slogans are theme line and tagline (Bovee, Arens 1994:274).

Occurrence of linguistic deviations is not only unique for the text, it has been, however, observed that figurative expressions and deviations are in fact commonly found in everyday speech. A copywriter while writing an advertisement must be aware of the fact that the language with deviations is commonly and widely used for the purpose of actual portrayal of the circumstances in which the advertisement is created. Advertisers frequently use language in ways which depart from convention (Widdowson 2007:45). 


\section{Linguistic Deviation}

Deviation is opposite to norm and refers to a selection of linguistic items outside the range of normally allowed selections. When people use a language, they must obey some rules (that is called norm). For example, an "s" or "es" must be added to the verb of the third singular present tense or a preposition must be followed by a noun or gerund. Deviation is the breaking of rules that others obey (Skorupa, Duboviciene 2005:98).

Being against linguistic principle purposively, deviation is sometimes entertaining, while sometimes - confusing. Linguistic categorization of deviation will be clearly classified in different types of advertisements, moreover, interpreting deviation not only has linguistic significance but also contains a commercial and pragmatic value for advertisers on the application and choice of deviation. To make the discussion complete, we could go for the complete linguistic analysis of deviations in advertising. In the framework of linguistics, there are several types of deviation: deviation of phonology, graphology, lexicon, grammar and collocation.

To know a language completely, one must know how to pronounce (phonology) and write the forms of the language units (graphology), that is, how to give them physical realization, one must memorize the vocabulary of that language (lexicon) and learn a set of rules (grammar) showing how the items of the vocabulary are to be used in constructing sentences, that is the formal aspect of the language. When deviation happens, it violates the norm from one aspect or another.

Phonological deviation. - There is not much scope for phonological deviations in advertising language, but it takes into consideration only those messages where the pronunciation of the word is different from the commonly accepted pronunciation. This deviation in the pronunciation might be due to the presence of deviation in the spelling of the word (Belch 2003:35).

I'm lovin' it.

$<$ https://corporate.mcdonalds.com/corpmcd.html> 
Apparently, McDonald's has transformed the "loving" to "lovin"'. Among teenagers, the pronunciation of [in] is much more popular, consequently [in] has been changed to [in] in teenager's daily oral English. Therefore, as the fashion trend is concerned, "McDonald's" makes this change intentionally to attract the attention of its main target consumers, that is, teenagers.

Different pronunciation creates different effect of hearing. The sound of [w] makes people feel the sense of wave; the sound of $[b]$ indicates that of blow, [d] is related to durable, while [ou] is that of simplicity and sorrow. The advertisement of Chips uses [p] three times to present the crispness of the chips.

\section{Pringles Potato Chips. \\ $<$ https://www.shutterstock.com/search/potato+chips+logo?im age_type $=$ photo $>$}

In advertising messages these phonological deviations are generally represented by the frequent appearance of alliteration, end rhyme, rhyme of the beginning and the end, homograph, etc. in advertisements.

The passionate pursuit of perfection.

(Lexus, Fortune, July $12^{\text {th }}$ )

Giving your ideas more room to roam.

(HP, Fortune, July 26 $6^{\text {th }}$ )

Levitra Quality counts, count on Levitra.

(Levitra, Fortune, July $12^{\text {th }}$ )

The first example is an illustration of alliteration of [p] in a car advertisement, from which we can feel the strong determination to make the car perfect. In the second example "room" and "roam" are similar to each other both in pronunciation and form. By associating these two together, the reader's mind is also expected to ramble. It is worthwhile to give some special attention to the third example. This is called deviation of homograph. The two "count"s are identical in form but different in meaning. The first "count" refers to "value 
and importance", while the second one means "rely on something (here Levitra is a name of a kind of medicine)". These two "count"s combine the sentence coherently and also enhance the idea of the good effect of the medicine (Chi and Hao 2013:85-89).

Graphological deviation. - This type of deviation is predominantly found in advertising messages. It is the simplest yet effective way to grab the attention of the readers. The deviation provides copywriters a freedom to go on making unlimited changes to the spelling of the words of interest while not disturbing the pronunciation at all. The orthographic devices such as selection of script, its color, type and size are normally used to draw the immediate attention of the consumers. English is rich in deviation of word spelling. For the sake of being emphatic, vivid, associative and conspicuous, spelling deviations come into wide and frequent use by repetition of morphemes, words and punctuations, capitalization, misplacement, deletion, addition, substitution and malapropism. This form of deviation not only retains the original meaning of the phrase but also adds information by putting brand into words and making it stick out and using numbers and symbols (Xiangjin 2004:167). As spelling represents pronunciation, any deviation in pronunciation will be definitely reflected in the written form.

- Putting brand into words and making it stick out.

A typical example of this is a series of advertisements for CNN in Time.

For peace of mind, stay connected.

(CNN, Time, Sep 6 ${ }^{\text {th }}$ )

Every perspe_tive, dime_sion, a_gle.

(CNN, Time, Sep $\left.6^{\text {th }}\right)$

In real advertisement, the bold letters of the first example are marked with red color, while the second one uses underlines to leave out several letters in the words. Whatever methods it uses, it is for foregrounding the brand of CNN (Chi and Hao 2013:85-89). 
- Using numbers and symbols

With Telekom Malaysia, it is always Good 4 Business.

(Telekom, Time, Aug 9th)

$A C N-2-A C N$ free calling.

(ACN, Fortune, July $26^{\text {th }}$ )

In this group, the two examples use numbers to replace words: 4 instead of "for" and 2 for "to", which has been very popular in today's daily life since the spread of the internet language and text messages. Numbers are more convenient to transfer the relevant meanings and attract more attention than the common words (Chi and Hao 2013:85-89).

A representative type of lexical deviation is coinage, the invention of new words or phrases. Being original and creative, words or expressions can always attract readers' attention, therefore, the strategy of coinage is widely used in advertisements.

The Orangemostest Drink in the world.

<https://www.ebay.com/b/Monster-Energy-Orange-Energy-

Drink-Advertising/165237/bn_83104034>

This advertisement creates the word "orangemostest", adding "most" and "est" as dual suffix after "orange". Firstly, the new word would refresh the readers' mind and be impressive. Also, the repeated emphasis on the good quality of the orange can win some credit for the product, to some extent.

- Coinage or Nonce-Formation Coinage appears most frequently when making up names of a product. The suffix "-ex" is an example, "-ex" is the suffix of top frequency in advertising copy, which is regarded as the clipping form of excellent. It is often used to describe precision instruments or products, such as "Rolex", "Memorex", "Pentax", etc. But nowadays many articles of everyday use benefit from it, like Kleenex (a facial tissue), Cutex (a nail polish), Purex (a decolourant), etc (Foster 2001:56). By adding "-ex" to form the name, the advertiser or manufacturer wants to emphasize the high quality of the product. 
The changing of the normal spelling is also a kind of coinage. For example, a kind of quick dissolving chocolate is called "Quik Chocolate". It seems that if we add the aphonic "c", the dissolving speed of the chocolate will be slowed down (Foster 2001:98).

- Functional conversion is to change a word's common part of speech, such as to use a verb as a noun or vice versa (Kenworthy 1991:187). To use a noun or an adjective as a verb is to combine the static state with a dynamic one for better linguistic appeal, while to change a noun into an adjective or vice versa is to emphasize the properties or state of the person or object and to make the language more vivid.

Eat smart. Be fit. Live well.

(Cooking Light, Fortune, July $26^{\text {th }}$ )

With solutions that are plat formed and system friendly, but more importantly, business-strategy friendly, too.

(IBM, Fortune, July 26 $6^{\text {th }}$ )

The first example changes the adjective "smart" to an adverb most possibly for rhyme. The other example applies the noun form "platform" to a verb, which means "to make a platform for buyers". The most frequently used strategy is replacing a word (of any word class) with the brand name, so that the brand name acquires syntactic features of original fictive word. This tendency is still used even after a hundred years.

Get that Pepsi feeling.

$<$ https://www.adsoftheworld.com/taxonomy/brand/pepsi>

In this advertisement, the word "Pepsi" acts as an adjective. Deviation of collocation refers to the combination of some words which normally cannot be collocated.

The next type is the deviation of Grammar. It has often been observed that advertising tends to chop up sentences into shorter bits by using full stops 
where ordinary prose would use commas or no punctuation at all. Leech referred to this phenomenon as "disjunctive syntax".

It's. Difficult. To. Stay. Competitive. If. You're. Always. Stopping. To. Upgrade. Your. HR. Technology. Outsourcing to Hewitt can help. Period.

(Hewitt, Fortune, Aug 23 ${ }^{\text {rd }}$ )

In this case, almost every word is followed by a full stop, which will cause some trouble to readers when going through the advertisement. By doing this, the advertiser wants to convey to his customers that if they don't choose the company's products, their HR technology will not be efficient and will prevent their competing with other companies, just like the difficulties they meet when reading the advertisement. The last word "period" again stresses the completeness of the sentence (Chi and Hao 2013:85-89).

\section{Conclusion}

Thus, we can conclude that among all the linguistic attention-attracting strategies employed in advertisements, language deviation needs special attention because it is regarded as the use of language that violates normal rules. Based on case studies of language deviation, one can see that deviation is widely used in advertising with good grounds. Well-adopted deviation in advertising can attract the audience to go through the advertisement and even persuade them to buy the products advertised. As a whole, the study of language deviation in advertisements can help to interpret the advertising communication.

\section{References:}

1. Belch, G.E. (2003) Advertising and Promotion: An Integrated Marketing Communications Perspective. London: Picador.

2. Bovee, C.L. and Arens, W.F. (1994) Contemporary Advertising. Oxford: Blackwell. 
3. Chi R. and Hao Y. (2013) Language Deviation in English Advertising. China: Changchun.

4. Foster, T. (2001) The Art and Science of the Advertising Slogan. Cambridge: CUP.

5. Kenworthy, J. (1991) Language in Action. New York: Longman.

6. Laspasanska, J. (2006) The Language of Advertising with the Concentration on the Linguistic Means and the Analysis of Advertising Slogans. New York: OUP.

7. Leech, G. (1972) English in advertising: A Linguistic Study of Advertising in Great Britain. English Language Series. London: Longman.

8. Pearson, C.J. and Nelson, E.P. (1994) Understanding and Sharing: An Introduction to Speech Communication. Athens: Ohio University.

9. Skorupa, P. and Duboviciene, T. (2005) Linguistic Characteristic of Commercial and Social Advertising Slogans. New York: Springer.

10. Vasiloaia, M. (2009) Linguistic Features of the Language of Advertising. Dordrecht \& Boston: D. Reidel Publishing Company.

11. Widdowson, H, G. (2007) Discourse Analysis. Oxford: OUP.

12. Xiangjin, T. (2002) English Word-Spelling Deviations and Their Semantic Meaning. Foreign Language Education. Oxford: Blackwell.

13. Yule, G. (2006) The Study of Language. Cambridge: CUP.

\section{Sources of Data:}

1. https://corporate.mcdonalds.com/corpmcd.html [Accessed February 2019].

2. https://www.ebay.com/b/Monster-Energy-Orange-Energy-Drink-Advertising/165237/bn_83104034 [Accessed February 2020].

3. https://www.adsoftheworld.com/taxonomy/brand/pepsi [Accessed February 2016]. 


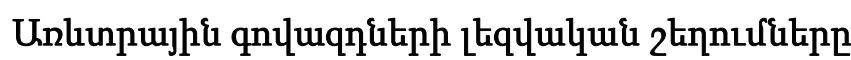

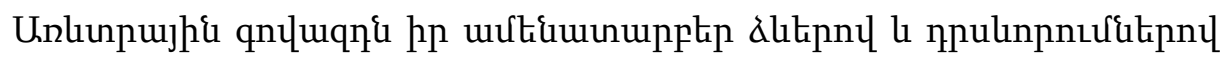

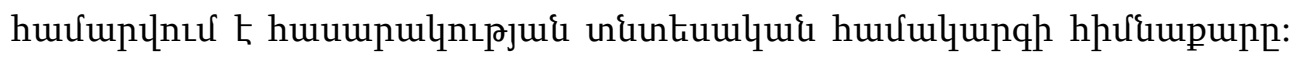

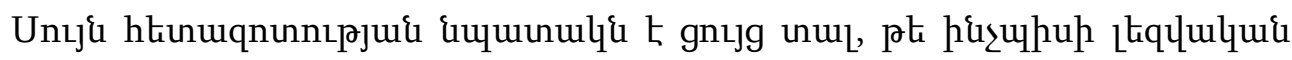

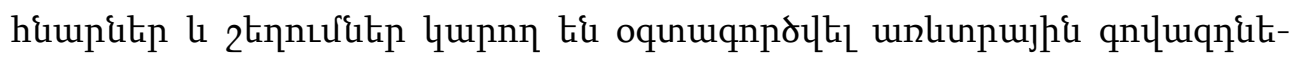

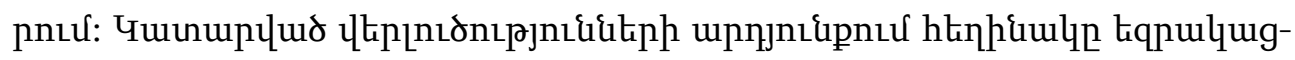

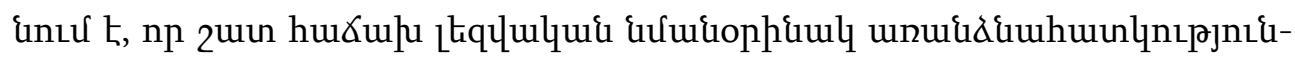

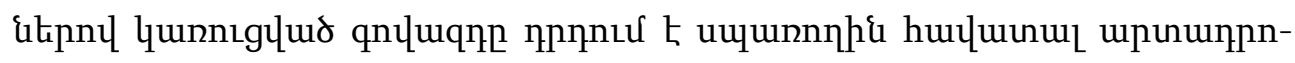

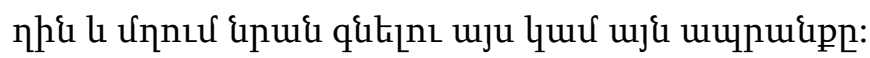

Received by the Editorial Board 10.06.2020

Recommended for publication by the reviewers 7.07.20

Accepted for print 30.09.2020 